\title{
Toxic impacts of a mixture of three pesticides on the reproduction and oxidative stress in male rats
}

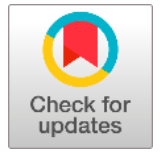

\author{
Narimene Bouabdallah ${ }^{a}$ Leila Mallem ${ }^{a b}$ | Cherif Abdennour ${ }^{2}$ iD | Amel Chouabbia | \\ Mohamed Tektak
}

aLaboratory of Animal Ecophysiology, Department of Biology, Faculty of Sciences, University Badji Mokhtar-Annaba, 23000 Annaba, Algeria. Faculty of Medicine Annaba, Department of Dental Medicine, University Badji Mokhtar-Annaba, 23000 Annaba, Algeria.

*Corresponding author: bouabdallahnarimene@gmail.com

\begin{abstract}
The present study investigated the toxic effect of a mixture of three pesticides (cypermethrin, mancozeb, and metalaxyl) on reproduction and oxidative stress parameters in male Wistar rats. Animals were treated at doses $1 / 60,1 / 30$, and 1/10 LD50 of each pesticide daily in the diet for 08 weeks. At the end of the treatment period, animals were sacrificed by decapitation. The results indicate a decrease in the absolute weight of testes and epididymis, the serum of testosterone hormone, and cholesterol levels. These parameters were significant reduced in males exposed to the mixed pesticides. A reduction in sperm concentration, motility, and viability also was observed. Besides, the ingestion of mixed pesticides at all three concentrations caused a significant decrease in GSH, GPx levels and an increase in MDA levels compared to the control group. This was accompanied by histopathological changes in testis and epididymis of rats such as seminiferous tubules degeneration, decreasing number of spermatogenic cells, edema, expansion of interstitial spaces, cell necrosis, and reducing the diameter of the epididymal tube compared to the control group. Thus, we strongly suggest that the mixture of pesticides causes damages to the male reproductive system.
\end{abstract}

Keywords: cholesterol, histopathology of testes and epididymis, MDA, testosterone

\section{Introduction}

Pesticide plays an important role in agricultural space or public health protection programs for preventing and controlling plants from pests and vector-borne diseases, leading to increased food production (Alewu and Nosire 2011). Although, the over-application or misuse of these pesticides caused a possible adverse effect on human and animal health (Balali-Mood 2008).

The population is exposed either simultaneously or sequentially to more than one pesticide every day via multiple pathways (contaminated food and water, household insecticides application). However, those routes are less dangerous to human life than the groups exposed daily for many hours, such as producers, pesticide workers, and farmers (Aktar et al 2009). The frequent use of pesticides in agricultural and commercial settings has led some researchers to study the effects of mixtures of these compounds as they co-occur in the environment (Trimble and Lydy 2006). Many studies demonstrated that exposure to pesticides might contribute to various diseases, including neurological, carcinogenic (Bassil et al 2007), respiratory (Hernández et al 2011), reproductive and developmental toxicity (Hanke and Jurewicz, 2004). Furthermore, many studies have shown that high occupational to pesticides may provoke oxidative stress damages to various physiological function systems as testicular function. (Ihsan et al 2011; Mehrpour et al 2014).
This study tested three chemical pesticides, an insecticide (Cypermthrin) and two fungicides (mancozeb and metalaxyl), which are all widely used in agriculture in the east of Algeria to control insect and fungal diseases in a variety of corps (Sukul and Spiteller 2000; Joshi et al 2005; Solat et al 2010). Many studies have investigated that cypermethrin and metalaxyl altered the nervous system and induced histochemical damage in liver tissues (Okdah 2005; Noaishi et al 2013). Likewise, mancozeb exposure can affect the function of the thyroid gland by decreasing serum thyroxine levels, thyroid peroxidase (TPO) activity, and iodine uptake (Goldner et al 2010). Moreover, they can induce histopathological changes in the liver of animals, such as vacuolation of hepatocytes, Necrosis, and infiltration of inflammatory cells (Elkhansa et al 2015).

The reproductive system is a sensitive structure that can be affected upon exposure to toxic compounds (Shakkebaek 2001). Male infertility is estimated at $40 \%$ of infertility cases (Sadock et al 2003), and it may be linked to exposure to pesticides (Sharma et al 2014). Recent studies have shown that cypermethrin, mancozeb, and metalaxyl affect spermatogenesis, reducing semen quality of the testes and epididymis in exposed males (Main et al 2002; Sunder 2002; Joshi et al 2005). Other researchers have found that pesticides could also disturb the hypothalamic-pituitarygonadal axis (Alaa-Eldin et al 2016). On the other hand, these toxicants can produce oxidative stress in reproductive tissues 
by forming free radicals (ROS), leading to cellular apoptosis in testis and epididymis and perturbation of antioxidant profile defenses.(Diazveliz 2004; Joshi et al 2010) Besides, excessive production of ROS can impair reproductive capacities by modifying sperm mobility, viability, and integrity of their membrane (Abd-Ellah et al 2015; Gririchi et al 2017). Thus, the toxicity potential of these pesticides has been extensively studied, and a great deal of data has been collected. However, about $95 \%$ of these studies have been conducted on individual compounds (Groten 2001). Although currently, the majority of pesticides are used in combination. The local manufacturers are formulating mixtures of ready-to-use pesticides (British 2013) instead of using individual ones, which may cause more health damage. The potential effects of these mixtures on the reproductive system remain unknown and poorly understood (Wade et al 2002).

Therefore, this research aimed to evaluate the adverse effects of the three pesticides mixture (cypermethrin, mancozeb, and metalaxyl) on the reproductive system and oxidative stress in male Wistar rats.

\section{Materials and Methods}

\subsection{Animals and treatment}

Twenty-seven male Wistar rats weighing between 200 to $250 \mathrm{~g}$ were obtained from the Animal Center of Alger in Algeria. The rats were acclimatized for two weeks, and the diet and water were given ad libitum. Animals were maintained in a good rearing condition of ambient temperature and a light-dark photoperiod. After the acclimation period, the animals were divided into four groups with eight rats each. Animals were treated with the mixed pesticide $1 / 60,1 / 30$, and $1 / 10$ LD50 of the used pesticides (Cypermethrin, Mancozeb, and Metalaxyl) daily in the diet for 08 weeks. At the end of treatment, animals were sacrificed by decapitation, blood and semen were collected. Serum was collected for hormone and cholesterol assays. The right testes and epididymis were excised and weighed. The right testis was frozen for sperm production and determination of oxidative stress parameters. The left one was processed for histopathology. Animals' treatments were authorized by the Ethical Committee of Animal Sciences at the University of Badji Mokhtar-Annaba, before starting the experimental work.

\subsection{Semen analysis}

Semen parameters (concentration and motility) were measured using Computer Assisted Semen Analysis (CASA). After decapitation, the semen was collected from a small opening in the epididymis cauda. About $1 \mu \mathrm{l}$ of semen was diluted in $0.09 \%$ physiological solution; after that, about $5 \mu \mathrm{L}$ of the mixture was placed in the Goldcyto counting chamber using a micropipette. This preparation was examined under a microscope connected to a microcomputer at a final magnification of $x 40$.

\subsection{Hypo-osmotic swelling (HOS) test}

The HOST test was used to evaluate the integrity of sperm by exposing a drop of sperm, derived from the epididymis cauda, to the hypo-osmotic solution composed of fructose and sodium citrate (Jeyendran 1984), after which 100 spermatozoa were observed. The number of live sperms (as shown by an inflation of the tail) were counted.

\subsection{Testosterone and cholesterol levels}

Testosterone levels were determined in serum rats by immunoassay analyzer Access 2. Cholesterol levels were estimated by the clinical chemistry analyzer (MINDRAY BS240), using commercial kits and colorimetric enzymatic method.

\subsection{Histology examination}

The organs were fixed in formol $10 \%$ and dehydrated in a series of [70-100\%] ethanol baths. Then, they were placed in paraffin at $58^{\circ} \mathrm{C}$ for inclusion. Sections of 4 to $6 \mu \mathrm{m}$ were prepared from paraffin blocks using a rotary microtome and then were stained with Hematoxylin-Eosin (H- E) using Martoja and Martoja (1967) method. All sections were photographed with a specific camera in a Leica microscope.

\subsection{Measurement of oxidative stress parameters}

Malondialdehyde (MDA) was measured according to the method described by Ohkawa et al (1979). Total glutathione (GSH) content in blood was evaluated by the method detailed by Weckbecker and Cory (1988). The Glutathione peroxidase activity was measured spectrophotometrically by the method of Flohé and Günzler (1984). The protein concentration was determined according to the Bradford method (1976).

\subsection{Statistical analysis}

Results were expressed as mean \pm SD. The statistical analysis of the data was performed by the test of $t$-Student pairs between the control group and each treated group. The statistical analysis was carried out by using the Graph Pad Prism software (version 5). Significant differences was considered when $* P<0.1,{ }^{* *} P<0.01, * * * P<0.001$.

\section{Results}

3.1. The effect of the pesticides mixture on the testis and epididymis absolute weight

There was no significant decrease in the weight of testis and epididymis in group G2. However, we noticed a significant reduction $(P<0.01, P<0.01)$ in groups treated with the medium (G3) and high doses of the mixture (G4) compared to the control group G1 (Figure 1).

\subsection{Effect of the mixture on sperm count, motility, viability}

It was remarked in (Table 1), a non-significant reduction in sperm count and motility in the treated group G2 compared to the control group G1. However, we have 
found a higher and very higher significant $(P<0.01, P<0.001)$ reduction in groups $\mathrm{G} 3$ and $\mathrm{G} 4$, respectively, compared to the control G1.

The non-significant influence of mixture pesticide in the normal sperm in group $\mathrm{G} 2$ compared to the control (Table 1), while in group $\mathrm{G} 3$ and $\mathrm{G} 4$, we observed a significant increase $(P<0.05, P<0.01)$ to compare to the control group. The malformation of the tail of sperm type $(A, B$, and $C)$ increased in groups $\mathrm{G} 3$ and $\mathrm{G} 4$, but group $\mathrm{G} 2$ non significantly affected $(P>0.05)$ compared to the control animals.

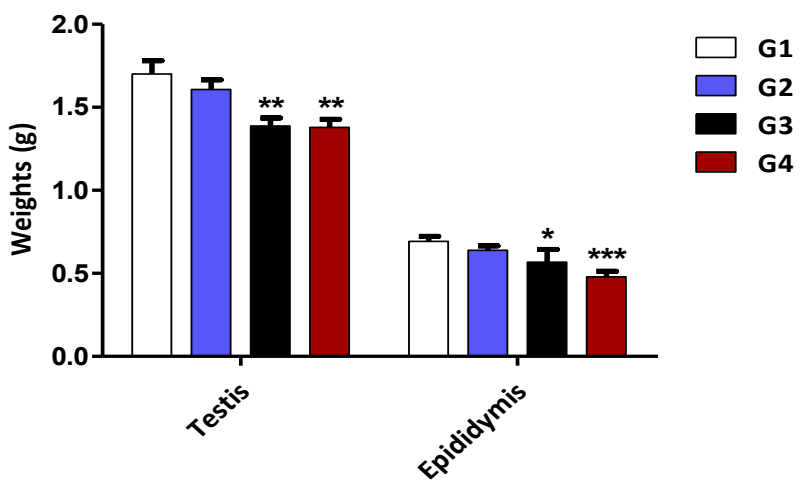

Figure 1 Effect of the mixture of pesticides on rats' testicular and epididymis weights $(\mathrm{MV} \pm \mathrm{SD}, \mathrm{n}=9) .{ }^{* *} p<0.01 ;{ }^{* *} p<0.001$.

\subsection{Effect of the mixture on serum testosterone and cholesterol level}

The change in testosterone level in all groups of rats is illustrated in figure 2 . The results show a non-significant change in serum testosterone levels of treated animals in group $\mathrm{G} 2$ compared to the control group $\mathrm{G} 1$. On the other hand, a significant reduction $(P<0.05, P<0.01)$ was deduced in groups $\mathrm{G} 2$ and $\mathrm{G} 3$ compared to the control group.

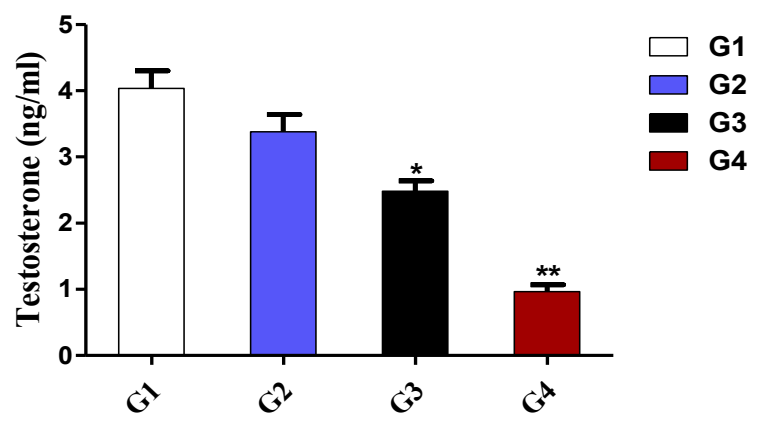

Figure 2 Evaluation of testosterone level $(\mathrm{ng} / \mathrm{ml})$ of rats exposed to mixture pesticide after eight weeks of treatment. Results are expressed as (Mean $\pm \mathrm{SD}, \mathrm{n}=8$ ). ${ }^{*} P<0.1 ; * * P<0.01$.

The results in figure 3 show a non-significant change in serum cholesterol levels of treated animals in group G2 compared to the control group $\mathrm{G} 1$. While, a higher significant increase $(P<0.05, P<0.01)$ was deduced in group $\mathrm{G} 2$ and $\mathrm{G} 3$ compared to the control group $\mathrm{G} 1$.

The control group (AA') showed normal spermatogenesis cells in different phases and the typical cell arrangement in the somniferous tubules. However, we have observed a reduction in spermatozoid cells in the lumen in the treated group $\left(B B^{\prime}\right)$. Also in the treated groups ( $C C^{\prime}$ and DD') showed degeneration in the seminiferous tubule. The interstitial spaces are enlarged due to tubular atrophy, edema, and a decrease in the number of sperms in the lumen.

The control groups (AA') showed the ducts' regular and normal external counter into the epididymal caput. Although, the treated groups (BB', CC'and DD') showed deformations into the external counter of epididymal ducts and reduction in spermatozoa number.

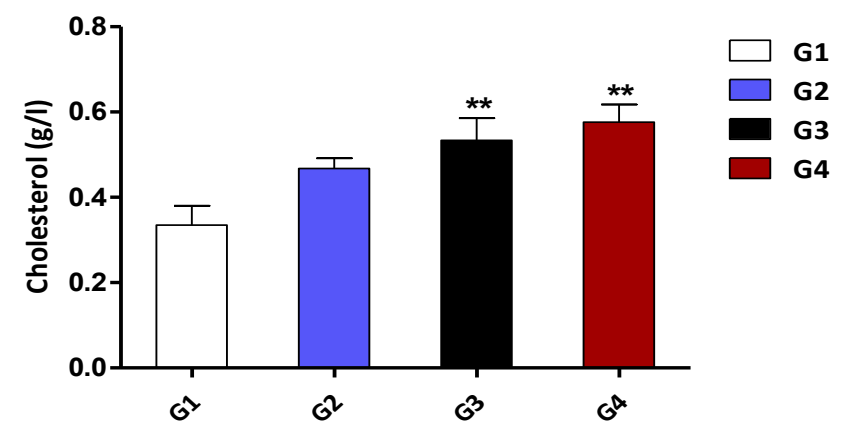

Figure 3 Evaluation of Cholesterol level $(\mathrm{g} / \mathrm{l})$ of rats exposed to mixture pesticide after eight weeks of treatment. Results are expressed as (Mean $\pm \mathrm{SD}, \mathrm{n}=8$ ). ${ }^{* *} P<0.01$.

\subsection{Effect of the mixture on Oxidative stress markers}

Results showed a non-significant increase of MDA level in testes and epididymis tissues of $\mathrm{G} 2$ animals compared to $\mathrm{G} 1$, as shown in Table 2. Besides, in $\mathrm{G} 3$ and $\mathrm{G} 4$, a significant increase $(P<0.01, P<0.001)$ of the MDA level in testis and epididymis tissues was observed compared to the control animals.

The pesticides mixture significant decreased the Gpx activity of testis and epididymis tissues in $\mathrm{G} 3$ and $\mathrm{G} 4$ groups compared to the control group G1. However, in the G2 group, we have found a non-significant decrease in the GPx level of testis and epididymis tissues compared to the control group G1.

GSH level in testes and epididymis is presented in Table 2. These results indicate that the treatment with a mixture of pesticides leads to the obtention of a highly significant decrease $(P<0.01)$ of GSH level in the G3 and G4 groups compared to the control group $\mathrm{G} 1$. On the other hand, the $\mathrm{G} 2$ group presented a non-significant reduction compared to the control one.

\section{Discussion}

Pesticides may directly damage spermatozoa, alter Sertoli and Leydig cell's function, or disrupt the endocrine function in any stage of hormonal regulation (hormone synthesis, release, storage, transport, and clearance; receptor recognition and binding) (Bretveld et al 2007).

The present study demonstrates a significant decrease in the mass of testis and epididymis associated with a decrease in testosterone level and the count, vitality, and 
motility of spermatozoa in rats treated with mixed pesticides: Cypermthrine, Metalaxyl, and Mancozebas compared to the control group. It is suggested that the decrease in the testis weight is probably via two effects. The anti-spermatogenic is the first one that can decrease the diameter and number of spermatogonia, spermatocytes, and spermatids in the seminiferous tubules of the testis. The second one is the anti- androgenic effect which reduces the number of sperms in testis tubules (Sakr and Shalaby 2011; Smith and Walker 2014; Yağmur et al 2020). Moreover, this result is consistent with those obtained by Lucier et al (1977) after the treatment with the mixture of the fungicides Maneb and Zineb in male adult rats.

Table 1 Evaluation of sperm concentration $\left(\times 10^{6} / \mathrm{ml}\right)$, sperm motility (\%) sperm viability (\%) of rats exposed to mixed pesticide after eight weeks of treatment. Results are expressed as (Mean $\pm \mathrm{SD}, \mathrm{n}=8)$. ${ }^{* *} P<0.01 ; * * * P<0.001$.

\begin{tabular}{|c|c|c|c|c|c|}
\hline \multicolumn{2}{|c|}{ Paramaters } & G1 & G2 & G3 & G4 \\
\hline \multicolumn{2}{|c|}{ Concentration $\left(\times 10^{6} / \mathrm{ml}\right)$} & $83.71 \pm 6.70$ & $72.73 \pm 4.19$ & $57.59 \pm 3.15^{* *}$ & $51.05 \pm 2.36^{* * *}$ \\
\hline \multicolumn{2}{|c|}{ Motility (\%) } & $58.92 \pm 3.14$ & $56.93 \pm 2.36$ & $39.79 \pm 4.83^{* *}$ & $21.91 \pm 3.53^{* * *}$ \\
\hline Viability & $\mathrm{N}$ & $40.52 \pm 1.57$ & $48.98 \pm 5.33$ & $58.75 \pm 5.41 *$ & $74.67 \pm 7.32 * *$ \\
\hline \multirow[t]{3}{*}{ (\%) } & A & $24.04 \pm 4.25$ & $19.94 \pm 1.95$ & $11.38 \pm 1.22^{*}$ & $9.69 \pm 1.67 * *$ \\
\hline & B & $19.24 \pm 1.14$ & $16.15 \pm 1.98$ & $12.70 \pm 0.71 * *$ & $9.57 \pm 2.63^{* *}$ \\
\hline & C & $16.20 \pm 2.77$ & $14.62 \pm 4.59$ & $4.41 \pm 1.46^{* *}$ & $2.11 \pm 0.88^{* *}$ \\
\hline
\end{tabular}

Table 2 Mean Testes and epididymis levels of MDA (nmol/g tissue), GSH (nmol/mg proteins), and GPx ( $\mu$ mol GSH/mg proteins) of rats treated with mixture pesticide after eight weeks of treatment. Results are expressed as (Mean $\pm \mathrm{SD} \mathrm{n}=8$ ). ${ }^{*} P<0.1 ;{ }^{* *} P<0.01 ;{ }^{* * *} P<0.001$.

\begin{tabular}{|c|c|c|c|c|c|c|}
\hline & \multicolumn{2}{|c|}{ MDA(nmol/g Tissue) } & \multicolumn{2}{|c|}{ GSH(nmol/mg proteins) } & \multicolumn{2}{|c|}{ GPx( $\mu \mathrm{mol} / \mathrm{GSH} /$ mgproteins) } \\
\hline & Testis & Epididymis & Testis & Epididymis & Testis & Epididymis \\
\hline G1 & $0.21 \pm 0.02$ & $0.16 \pm 0.03$ & $37.86 \pm 2.05$ & $21.06 \pm 1.58$ & $0.20 \pm 0.016$ & $0.14 \pm 0.011$ \\
\hline G2 & $0.25 \pm 0.02$ & $0.21 \pm 0.02$ & $35.69 \pm 3.07$ & $21.06 \pm 1.58$ & $0.18 \pm 0.009$ & $0.12 \pm 0.013$ \\
\hline G3 & $0.40 \pm 0.03 * *$ & $0.38 \pm 0.04^{* *}$ & $22.05 \pm 3.061 * *$ & $16.3 \pm 0.82 * *$ & $0.12 \pm 0.01 *$ & $0.08 \pm 0.01 *$ \\
\hline G4 & $0.42 \pm 0.04^{* *}$ & $0.44 \pm 0.04 * * *$ & $18.78 \pm 2.98 * *$ & $11.14 \pm 1.34 * * *$ & $0.10 \pm 0.01^{* *}$ & $0.04 \pm 0.01 * * *$ \\
\hline
\end{tabular}

Similarly, other studies demonstrate the same effect after treatment animals with mancozeb. Sunder et al (2002) observed that the mixture of (Metalaxyl + mancozeb) caused alterations in testis tissues, a disruption of germinal epithelium, atrophy of the seminiferous tubules causing androgen insufficiency state, and atrophy of Leydig cells leads to decreased testis weight. It can also be probably due to the loss of histoarchitecture, where the atrophy of germ cells supported the reduction in organ weight (Desai et al 2016). Similar effects revealed the same data after oral intubation with Cypermthrin for only 30 days (Joshi et al 2010; Assayed et al 2008). It means that the reduction in testicular and epididymis mass could be linked to the histological changes in the male reproductive system (Jensen et al 2006). Our histological examination showed alterations in testicular tissue of rats after mixed pesticide's treatment as well as degeneration in somniferous tubules with loss of sperm, and reduction of spermatogenic cells number in some somniferous tubules, expansion of interstitial spaces, and induction of cell necrosis accompanied by apical sloughing in the section of testes in the treated groups as compared to the control groups (Elbetiha et al 2001; Ksheerasagar and Kaliwal 2003).

Our histologic examinations of the testes and epididymis sections (Figure 4) revealed that the used mixture of the pesticides induced in our experimental conditions in the seminiferous reduced spermatozoa in the lumen, especially in groups treated with the medium and high doses, demonstrating seminiferous tubule degeneration. The interstitial spaces are enlarged due to tubular atrophy, edema, and decreased sperms in the lumen. Similarly, the section of the epididymis showed deformations into the external counter of epididymal ducts and reduction in spermatozoa number as the compared control group. 
This result is also in agreement with the study of Sharma and Singh (2010) that treating rats with cypermethrin could decrease epididymis mass by reducing sperm concentration and the degenerative change in epididymal tissues. Similarly, Khan and Sinha (1994) have reported that mancozeb could lead to the same effect by a decrease of sperm count and the increase of sperm with aberrant head morphology in the epididymis tube (Figure 5).

On the other hand, our research also showed reduced sperm motility after using a mixture of pesticides for eight weeks after treating rats. We hypothesize that the mixture has probably caused a morphological perturbation in the intermediate piece and the flagellum, responsible for spermatozoa movement. It cited that cypermethrin may affect sperm motility by altering enzymatic activities of mitochondria (oxidative phosphorylation); thus, it stops ATP formation responsible for the spermatozoa movement (Bedford 1983). This result agrees with the finding of Pant et al (1995), who indicated the same result after exposing rats to carbofuran, which belongs to the same family of mancozeb.
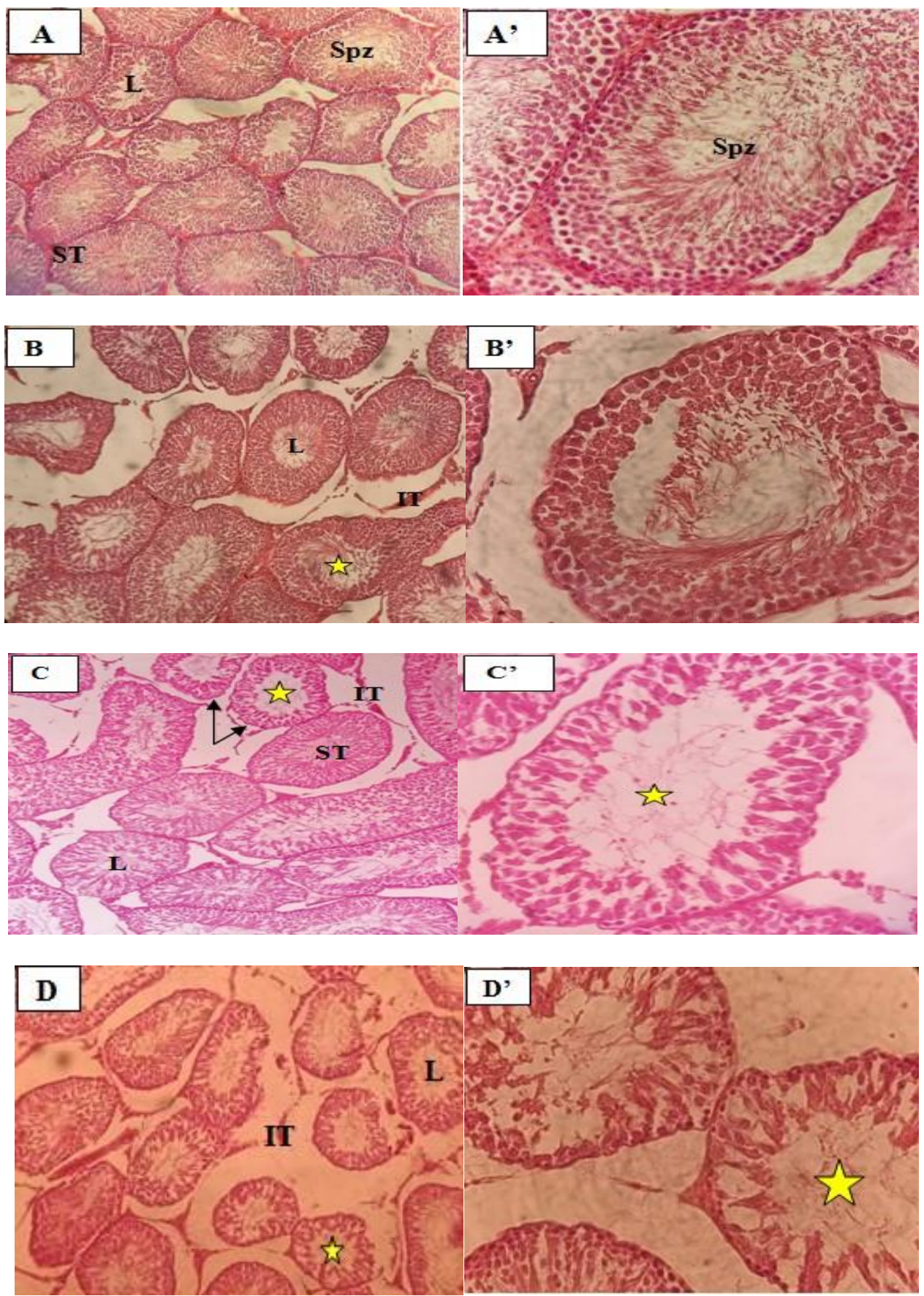

Figure 4 Photomicrography of transverse section in the somniferous tubules of the testes in the control and treated group (H.E.100X, 400X). Legend: ST: seminiferous Tubules; L: lumen; Spz: spermatozoa; Arrow: atrophic tubules; yellow star: a reduction in spermatozoid. 
In terms of sperm viability, we found a decline in viable sperms collected in cauda epididymis after the treatment by mixed-used pesticides compared to the control group. Research showed that treatment with cypermethrin leads to a reduction in sperm vitality in the testis of rats. This is following the results of Singh et al (2014), who have noticed a drop in sperm vitality after exposing male rats to cypermethrin for 14 days.
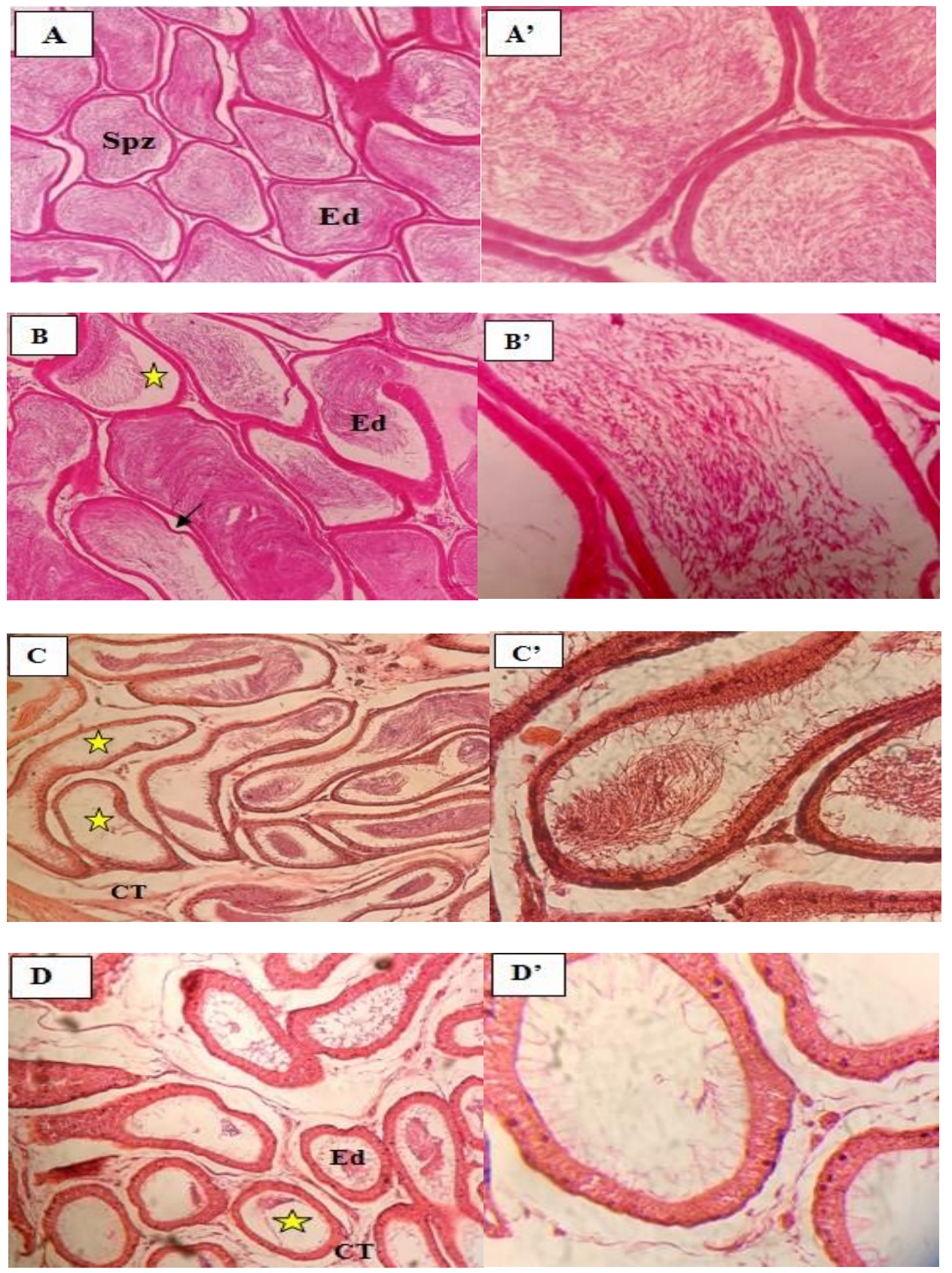

Figure 5 Photomicrographs of sections epididymis in all groups after the treatment with the mixture of pesticides compared to the control (H.E.100X, 400X). Legend: Ed: epididymis duct; arrow deformation; CT: connective tissue; yellow star: reduction in spermatozoid; Spz: spermatozoa.

Testosterone plays a clear and vital role in developing male reproductive tissues, especially the testis (Elbetieha et al 2001). The pesticides mixture significant reduces serum testosterone level in treated animals compared to the control group. The mixture of pesticides may probably affect the hypothalamus-pituitary axis, where the $\mathrm{GnRH}$ is produced, responsible for the liberation of $\mathrm{LH}$. This hormone (LH) stimulates Leydig cells to produce testosterone; hence, a decrease in LH may lower testosterone levels (Joshi et al 2011). It has been further reported that pyrethroid insecticides which are the family of cypermethrin, can cause mitochondrial membrane fragility in Leydig cells and damage testosterone biosynthesis by diminished the transport of cholesterol into the mitochondria and reducing the transformation of cholesterol to pregnenolone in the cells, thus decreasing testosterone production (Zhang et al 2007). 
This is in perfect concordance with our testosterone results and cholesterol concentration in the treated groups compared to no-treated rats.

The reproductive toxicity of pesticides may cause the low sperm count through the neuro-endocrine-mediated phenomenon and a hormone-disrupting property. This hypothesis suggested by Yousef et al (2003), leading to low sperm count, could be that pesticides interact competitively with androgen receptors and sex hormone-binding globulin, causing the endocrine system to disrupt. The present study indicated that the treatment with used mixed pesticides induces a decrease in sperm parameters: concentration, mobility, and vitality of spermatozoa. Concerning the rate vitality of spermatozoa in the treated animals, the data indicate a significant decrease in the live spermatozoa. Likewise, Sunder (2002) indicated that treating rats with a mixture of (metalaxyl + mancozeb) at the dose of $500 \mathrm{mg} / \mathrm{kg}$ for 30,60 , and 90 days induced a remarkable decrease in live sperm's percentage.

The disturbances in the reproductive system and quality of sperm might be attributed to oxidative stress (Agarwal and Said 2005). Reproductive organs are very susceptible to damage by free radicals due to their high content on polyunsaturated fatty acids (Noblanc 2011; Lopez 2007). Malondialdehyde (MDA) is the final result of lipid peroxidation operation that might be defined as an oxidative deterioration of polyunsaturated lipids (Debnath and Mandal 2000). Treating rats with mixed pesticides induced a significant increase in MDA levels in testis and epididymis tissues. It has been shown that the accumulation of cypermethrin in testicular and epididymis tissue led to membrane degeneration and extensive formation of free radicals.

Similarly, Sharma et al (2013) have found that the level of MDA was increased in the testis of rats after 14 days of treatment with pesticides. In addition, cypermethrin can affect mitochondria and stop the adenosine triphosphate generation, which leads to block the cell's main energy source, causing mitochondrial dysfunction and producing high concentrations of free radical (Joshi et al 2010). In another study, mancozeb can also increase MDA levels in testis and epididymis organs. Different studies have demonstrated that the toxicity of mancozeb is related to the association of its organic molecule to magnesium (Domico et al 2007). A different generation of ROS by $M n$ incorporates the oxidation of $\mathrm{Mn} 2$ to $\mathrm{Mn} 3$, which catalyzes DA oxidation with the production of toxicant reactive intermediaries (Diazveliz 2004). Kaloyanova et al (1991) reported that oxidative stress is one of the indications of metalaxyl-induced poisonousness.

Under oxidative stress, the concentration of glutathione peroxidase (GPx), which is supposed to act against the free radicals, changed in both testis and epididymis tissues. In the current study, Cypermthrin treatment was found to induce GPx reduction. This result agrees with Singh et al (2014), who has also deduced a reduction in GPx level in testis and epididymis tissue of rats exposed to cypermethrin (3.83 $\mathrm{mg} / \mathrm{kg}$ BW) for 14 days. Therefore, the reduction of GPx results from the decreased activity of glutathione (Sun 2007). Mancozeb can also cause the same result of Cypermethrine by impairment activities of those enzymes, indicating then the failure of the primary antioxidant system to act against free radicals (Ayala et al 2014). A decrease in glutathione (GSH) in testis and epididymis after exposure to the mixed pesticides in our experimental conditions could be related to the increase of GSH utilization because it acts with $\mathrm{SH}$ as a catalyst for the disulfide exchange reaction and finally contributes to (ROS) detoxification (Raina et al 2009). Other research explained that deltamethrin reduced the GSH activity in the testis (Singh et al 2014).

\section{Conclusions}

Exposure to a combination of pesticides by alimentation for 60 consecutive days may induce reproductive toxicity in male rats manifested by decreases in the fertility index, the weight of the sexual organs, semen characteristics, serum testosterone, and cholesterol, as well as severe histological changes. Also, it resulted in lipid peroxidation and depletion of antioxidant enzymes in the testes and epididymis of the rat. These results highly impose the necessity for more itemized testing of the toxicity of pesticide mixture exposure, especially by alimentation, and caution should be exercised in their handling as lengthy exposure time might lead to damaging health effects.

\section{Acknowledgments}

The Research Laboratory of Animal Ecophysiology supported this research. Thanks are given to Dr. Cheniki, Director of Histological Laboratory for the histological study, Hospital El-Bouni (Algeria).

\section{Conflict of Interest}

The authors declare that there is no conflict of interest with this work.

\section{Funding}

This research did not receive any financial support.

\section{References}

Abd-Ellah M, Aly H, Mokhlis H,\& Abdel-Aziz A (2015) Quercetin attenuates di-(2-ethylhexyl) phthalate-induced testicular toxicity in adult rats. Human \& Experimental Toxicology. doi: 10.1177/0960327115580602.

Agarwal A, and Said T M (2005) Oxidative stress, DNA damage and apoptosis in male infertility: a clinical approach. BJU International.doi:10.1111/j.1464410x.2005.05328.x

Aktar W, Sengupta D, Chowdhury A (2009) Impact of pesticides use in agriculture: their benefits and hazards. Interdisciplinary Toxicology. doi: 10.2478/v10102-009-0001-7.

Alaa-Eldin E A, El-Shafei D A, and Abouhashem N S (2016) Individual and combined effect of chlorpyrifos and cypermethrin on reproductive system of adult male albino rats. Environmental Science and Pollution Research. doi: 10.1007/s11356-016-7912-6

Alewu B and Nosiri C (2011).Pesticides and Human Health. Pesticides in the Modern World. Effects of Pesticides Exposure. doi: 10.5772/18734 
Assayed M, Salem H, Khalaf A (2008) Protective effects of garlic extract and vitamin $C$ against cypermethrin reproductive toxicity in male rats. Research Journal of Veterinary Sciences. doi: 10.3923/rjvs.2008.1.15.

Ayala A, Muñoz MF, Argüelles S (2014) Lipid Peroxidation: Production, Metabolism, and Signaling Mechanisms of Malondialdehyde and 4-Hydroxy2-Nonenal. Oxidative Medicine and Cellular Longevity. doi: $10.1155 / 2014 / 360438$

Balali-Mood M, Balali-Mood K (2008) Neurotoxic disorders of organophosphorus compounds and their managements.Archives of Iranian medicine 11:65-89.

Bassil K, Vakil C, Sanborn M, Cole D.C, Kaur JS, Kerr KJ (2007) Cancer health effects of pesticides.Systematic review. Canadian Family Physician 53: 17041711.

Bedford JM (1983) Significance of the Need for Sperm Capacitation before Fertilization in Eutherian Mammals. Biology of Reproduction. doi: 10.1095/biolreprod28.1.108

Bradford MM (1976) A rapid and sensitive method for the quantitation of microgram quantities of protein utilizing the principle of protein-dye binding. Analytical Biochemistry 72:248-254

Bretveld R, Brouwers M, Ebisch I,\&Roeleveld N (2007) Influence of pesticides on male fertility. Scandinavian Journal of Work. Environment Health. doi: 10.5271/sjweh.1060

British Colombia (2013) Human Pesticide Exposure butyrylcholinesterase and acetylcholinesterase by the organophosphate chlorpyrifos oxon. Toxicology and Applied Pharmacology 241:135-142.

Debnath D, and Mandal TK (2000) Study of quinalphos (an environmental oestrogenic insecticide) formulation (Ekalux 25 E.C.)-induced damage of the testicular tissues and antioxidant defence systems in Sprague-Dawley albino rats. Journal of Applied Toxicology.

Desai KR, Moid N, Patel PB, and Highland HN (2016) Evaluation of Deltamethrin induced reproductive toxicity in male Swiss Albino mice. Asian Pacific Journal of Reproduction. doi: 10.1016/j.apjr.2015.12.004

Diazveliz G (2004) Behavioral effects of manganese injected in the rat substantia nigra are potentiated by dicumarol, a DT-diaphorase inhibitor Pharmacology Biochemistry and Behavior. doi: 10.1016/j.pbb.2003.10.016.

Domico L, Cooper K, Bernard L, Zeevalk G (2007) Reactive oxygen species generation by the ethylene-bis-dithiocarbamate (EBDC) fungicide mancozeb and its contribution to neuronal toxicity in mesencephalic cells. NeuroToxicology . doi: 10.1016/j.neuro.2007.04.008.

Elbetieha A, Da'as SI, Khamas W, Darmani H (2001) Evaluation of the Toxic Potentials of Cypermethrin Pesticide on Some Reproductive and Fertility Parameters in the Male Rats. Archives of Environmental Contamination and Toxicology. doi: 10.1007/s002440010280.

ElkhansaYahia, Mohamed Amine Aiche, AmelChouabia, Mohamed Salah Boulakoud (2015) Thyroid Disruption and Infertility after Chronic Exposure to Mancozeb.Advances in Environmental Biology 9:96-102.

Flohe L and Gunzler WA (1984) Analysis of glutathione peroxidase. Methods of Enzymolog 105:114-121.

Girish BP, Reddy PS (2017) Forskolin ameliorates mancozeb-induced testicular and epididymal toxicity in Wistar rats by reducing oxidative toxicity and by stimulating steroidogenesis. Journal of Biochemical and Molecular Toxicology. doi: 10.1002/jbt.22026

Goldner WS, Sandler DP, Yu F, Hoppin JA, Kamel F, Le Van TD (2010) Pesticide Use and Thyroid Disease Among Women in the Agricultura Health Study.American Journal of Epidemiology. doi: 10.1093/aje/kwp404.

Groten JP, Feron VJ, \&Sühnel J (2001) Toxicology of simple and complex mixtures. Trends in Pharmacological Sciences. doi: 10.1016/s0165-6147 (00)01720-x

Hanke W, Jurewicz, J (2004) The risk of adverse reproductive and developmental disorders due to occupational pesticide exposure: an overview of current epidemiological evidence. International Journal of Occupational Medicine and Environmental Health 17:223-243.

Hernández AF, Parrón T, Alarcón R (2011) Pesticides and asthma. CurrOpin
Allergy Clinlmmunol 11: 90-96.

Ihsan A, Wang $X$, Liu Z, Wang $Y$, Huang $X$, Liu $Y$, Huan $Y$, Hongfei Zhang $H$ Li T, Yang C, Yuan $Z$ (2011) Long-term mequindox treatment induced endocrine and reproductive toxicity via oxidative stress in male Wistar rats. Toxicology and Applied Pharmacology. doi: 10.1016/j.taap.2011.02.020

Jensen TK, Bonde JP, Joffe M (2006) The influence of occupational exposure on male reproductive function. Occupational Medicin. doi: 10.1093/occmed/kql116

Jeyendran RS, Van der Ven HH, Perez-Pelaez M, Crabo BG, and Zaneveld UD (1984) Development of an assay to assess the functional integrity of the human sperm membrane and its relationship to other semen characteristics. Reproduction. doi: 10.1530/jrf.0.0700219

Joshi SC. Bansal B, and Jasuja ND (2010) Evaluation of reproductive and developmental toxicity of cypermethrin in male albino rats. Toxicological and Environmental Chemistry. doi: 10.1080/02772248.2010.537441.

Joshi SC, Gulati N, Gajraj A (2005) Evaluation of toxic impacts of mancozeb on testis in rats. Asian Journal of experimental Biological Science 19:73-83.

Kaloyanova F, Ivanova-Chemishanska L, Zaykov H, Baynova A, Mihaylova A, Mircheva V, Anton G, Shumkov N, Vergieva T and HalZ (1991) Toxicological evaluation of agromet (Metalaxyl) preparation. Journal of Hygiene. Journal Epidemiology, Microbiology, Immunology 35:375-382.

Khan PK\&Sinha SP (1994) Impact of higher doses of vitamin C in modulating pesticide genotoxicity. Teratogenesis, Carcinogenesis and Mutagenesis doi: 10.1002/tcm.1770140404

Ksheerasagar LR, Kaliwal BB (2010) Effect of Mancozeb on Thyroid, Testis, AccessoryReproductive Organs and Biochemical Constituents in Albino Mice. Recent Research in Science and Technology 2:07-170.

Lopez O, Hernandez A, Rodrigo L, Gil F, PENA G, Serrano J, Pla A (2007) Changes in antioxidant enzymes in humans with long-term exposure to pesticides. Toxicology Letters. doi: 10.1016/j.toxlet.2007.05.004.

Lucier GW, Lee IP, Dixon RL (1977) Effects of environmental agents on male reproduction. In Johnson, A.D., Grames, W.R. (Eds.), the Testis, vol. IV. Academic Press, New York.

Mani U, Islam F, Prasad AK, Kumar P, Kumar VS, Maji BK, Dutta KK (2002) Steroidogenic alterations in testes and sera of rats exposed to formulate Fenvalerate by inhalation. Human and Experimental Toxicology. doi: 10.1191/0960327102ht298oa.

Martoja R, and Martoja M (1967) Initiation aux techniques de I'histologie animale. (ed) Masson and Cie Paris, pp. 345-346.

Mehrpour O, Karrari P, Zamani N, Tsatsakis AM, Abdollahi M (2014) Occupational exposure to pesticides and consequences on male semen and fertility.A review. Toxicology Letters. doi: 10.1016/j.toxlet.2014.01.029.

Noaishi MA, Allah AA, Afify MM (2013) Oral and dermal exposure of chlorpyrifos and cypermethrin mixture induced cytogenetic, histopathological damage and oxidative stress in rats. Journal of American Science 9:56-65

Noblanc A, Kocer A, Chabory E, Vernet P, Saez F, Cadet R, Drevet JR (2011) Glutathione Peroxidases at Work on Epididymal Spermatozoa. An Example of the Dual Effect of Reactive Oxygen Species on Mammalian Male Fertilizing Ability. Journal of Andrology. doi: 10.2164/jandrol.110.012823.

Ohkawa H, Ohishi N, Yagi K (1979) Assay for lipid peroxidation in animal tissues by thiobarbituric acid reaction. Analytical Biochemistry 95:351-358.

Okdah YA (2005) Effect of antox on metalaxyl fungicide induced histological and histochemical changes in liver of albino mice. Egyptian German Society of Zoology 48:205-16

Pant N, Prasad A, Srivastava S,Shankar R, Srivastava S (1995) Effect of oral administration of carbofuran on male reproductive system of rat. Human \& Experimental Toxicology. doi: 10.1177/096032719501401106

Raina R, Verma PK, Pankaj NK, Kant V (2009) Ameliorative effect of alpha tocopherol on cypermethrin-induced oxidative stress and lipid peroxidation in Wistar rats. International Journal of Medicine and Medical Sciences 1:396399. 
Sadock BJ, Sadock VA (2003) Philadelphia: Lippincott Williams and Wilkins. 9th (ed) Kaplans and Sadocks Symptoms of Psychiatry Behavioral Sciences Clinical Psychiatry, pp. 872-4.

Sakr Saber A, and Somya Y Shalaby (2011) Ginger extract protects metalaxylinduced histomorphological and histochemical alterations in testes of albino mice.Journal of Applied Pharmaceutical Science 1:36-42.

Shakkebaek NE, Rajpert-De Meyts E,Main KM (2001) Testicular dysgenesis syndrome. An increasingly common developmental disorder with environmental aspects. Human Reproduction 16:972-978.

Sharma P, and Singh R (2010) Protective Role of Curcumin on Lindane Induced Reproductive Toxicity in Male Wistar Rats. Bulletin of Environmental Contamination and Toxicology. doi: 10.1007/s00128-010-9942-y.

Sharma P, Huq AU, Singh R (2013) Cypermethrin induced reproductive toxicity in male Wistar rats. Protective role of Tribulus terrestris. Journal of Environmental Biology 34:857-862.

Sharma P, Huq AU, Singh R (2014) Cypermethrin-induced reproductive toxicity in the rat is prevented by resveratrol. Journal of Human Reproductive Sciences. doi: 10.4103/0974-1208.138867.

Singh R, Jan M, and Sharma P (2014) Dose-dependent effect of deltamethrin in testis, liver, and Kidney of Wistar rats. Toxicology International. doi: 10.4103/0971-6580.139789

Smith LB, Walker WH (2014) The regulation of spermatogenesis by androgens. Seminars in Cell \& Developmental Biology. doi: 10.1016/j.semcdb.2014.02.012

Solati J, Hajikhani R, Zaeim RT (2010) Effect of cypermthrin on sexual behavior and plasma concentrations of pituitary-gonadal hormones. International Journal of Fertility and Sterility 4:23-28.

Sukul P, Spiteller M (2000) Metalaxyl persistence, degradation, metabolism and analytical methods. Reviews of Environmental Contamination and Toxicology 164:1-26.
Sun M, Xu PP, Ren Y, Li YF, Zhong YF, Yan H (2007) Protective effect of melatonin on oxidative damage by Deltamethrin in rat brain. Zhonghua Lao Dong Wei Sheng Zhi Ye Bing ZaZhi 25:155-8.

Sunder SR (2002) Evaluation of genotoxic cellular and morph physiological effects of a fungicide combination metalaxyl mancozeb in male rats. Cell tissue research 5:299-302.

Trimble AJ, and Lydy MJ (2006) Effects of Triazine Herbicides on Organophosphate Insecticide Toxicity in Hyalellaazteca. Archives of Environmental Contamination and Toxicology. doi: 10.1007/s00244-0050176-7.

Yousef MI, El-Demerdash FM, Al-Salhen KS (2003) Protective Role of IsoflavonesAgainst the Toxic Effect of Cypermethrin on Semen Quality and Testosterone Levels of Rabbits. Journal of Environmental Science and Health, Part B. doi: 10.1081/pfc-120021666.

Wade MG, Foster W G, Younglai E V, McMahon A, Leingartner K, Yagminas A, Blakey D, Fournier M, Desaulniers D, Hughes C L (2002) Effects of Subchronic Exposure to a Complex Mixture of Persistent Contaminants in Male Rats: Systemic, Immune, and Reproductive Effects. Toxicological Sciences. doi: 10.1093/toxsci/67.1.131

Weckbecker G, and Cory JG (1988) Ribonucleotide reductase activity and growth of glutathione-depleted mouse leukemia L1210 cells in vitro. Cancer Letters 40:257-264.

Yağmur Emre Arıcan1, DamlaGökçeoğlu Kayalı2, Bahar Ulus Karaca1, Tuğçe Boran1, NarinÖztürk3, AlperOkyar3, Feriha Ercan2 \&Gül Özhan (2020) Reproductive effects of subchronic exposure to acetamiprid in male rats. Scientific Reports 10:89-85.

Zhang SY, Ito Y, Yamanoshita O, Yanagiba Y, Kobayashi M, Taya K, Li C, Okamura A, Miyata $M$, Ueyama J, Lee $\mathrm{CH}$, Michihiro Kamijima $M$, Nakajima T (2007) Permethrin May Disrupt Testosterone Biosynthesis via Mitochondrial Membrane Damage of Leydig Cells in Adult Male Mouse. Endocrinology. doi: 10.1210/en.2006-1497. 